\title{
DETERMINASI SERVANT LEADERSHIP, KARAKTERISTIK INDIVIDU, MOTIVASI KERJA, DAN KEPUASAN KERJA TERHADAP KOMITMEN GURU DI SMAN 1 GIANYAR
}

\author{
Ayu Ratna, I Nyoman Natajaya, Kadek Rihendra Dantes \\ Jurusan Administrasi Pendidikan \\ Universitas Pendidikan Ganesha \\ Singaraja, Indonesia
}

\begin{abstract}
e-mail: ayuratna561@gmail.com,nyoman.natajaya@pasca.undiksha.ac.id. rihendra.dantes@pasca.undiksha.ac.id
\end{abstract}

\begin{abstract}
Abstrak
Penelitian ini bertujuan untuk mengetahui determinasi servant leadership, karakteristik individu, motivasi kerja, dan kepuasan kerja terhadap komitmen guru di SMAN 1 Gianyar. Penelitian ini adalah penelitian "ex-post facto" dengan sampel yaitu sebanyak 66 orang. Alat pengumpul data berupa kuesioner, analisis data digunakan teknik regresi sederhan, regresi ganda, dan korelasi parsial. Hasil penelitian menunjukkan bahwa: (1) terdapat determinasi yang signifikan servant leadership terhadap komitmen guru SMAN 1 Gianyar, dengan sumbangan efektif sebesar 7,64\%, (2) terdapat determinasi yang signifikan karakteristik individu terhadap komitmen guru, dengan sumbangan efektif sebesar 15,16\%, (3) terdapat determinasi yang signifikan motivasi kerja terhadap komitmen guru dengan sumbangan efektif sebesar $6,47 \%$, (4) terdapat determinasi yang signifikan karakteristik individu terhadap komitmen guru, dengan sumbangan efektif sebesar $28,50 \%$, (5) secara bersama-sama, terdapat determinasi yang signifikan servant leadership, karakteristik individu, motivasi kerja, dan kepuasan kerja terhadap komitmen guru dengan determinasi sebesar 57,80\%.
\end{abstract}

Kata Kunci : servant leadership, karakteristik individu, motivasi kerja, kepuasan kerja, komitmen guru

This study aims to determine the determination of servant leadership, individual characteristics, work motivation, and job satisfaction on teacher commitment in SMAN 1 Gianyar. This research is an "ex-post facto" study with a sample of 66 people. Data collection tools in the form of questionnaires, data analysis by using simple regression techniques, multiple regression, and partial correlation. The results showed that: (1) there was a significant determination of servant leadership towards the commitment of teachers of SMAN 1 Gianyar, with an effective contribution of $7,64 \%$, (2) there was a significant determination of individual characteristics of teacher commitment, with an effective contribution of $15,16 \%$, (3) there is a significant determination of work motivation towards teacher commitment, with an effective contribution of $6,47 \%$, (4) there is a significant determination of individual characteristics of teacher commitment, with an effective contribution of $28.50 \%$, (5) there is a significant determination simultaneously of servant leadership, individual characteristics, work motivation, and job satisfaction on teacher commitment with a determination of $57,80 \%$.

Keywords: servant leadership, individual characteristics, work motivation, job satisfaction, teacher commitment 


\section{PENDAHULUAN}

Seorang guru dikatakan profesional harus memilki komitmen yang tinggi. Menurut Palta (2018) dalam penelitiannya pada 149 guru menyebutkan bahwa komitmen guru yang rendah memiliki konsekuensi negatif individu dan organisasi seperti terlambat bekerja, absen, kinerja rendah dan bahkan meninggalkan pekerjaan. Guru yang memilki komitmen akan meningkatkan kualitas kerjanya, yang selanjutnya menentukan mutu pendidikan.

Dalam sistem persekolahan, lulusan merupakan titik pusat tujuan, lulusan berkualitas tidak mungkin terwujud tanpa proses pendidikan yang bermutu. Proses pendidikan yang bermutu tidak mungkin ada tanpa organisasi persekolahan yang tepat. Untuk memajukan organisasi yang tepat diperlukan pimpinan yang memadai, dan pemimpin itu sendiri harus mendapat dukungan komitmen dari seluruh perangkat sekolah.

Dalam hal ini kepala sekolah sebagai seorang pemimpin (leader) harus memiliki gaya kepemimpinan (leadership) yang bisa diterima bawahannya. Gaya kepemimpinan adalah sikap, gerak-gerik atau lagak yang dipilih oleh seseorang pemimpin dalam menjalankan tugas kepemimpinannya. Gaya yang dipakai oleh seorang pemimpin satu dengan yang lain berlainan tergantung situasi dan kondisi kepemimpinannya. Berkaitan dengan hal ini bahwa kepala sekolah selain sebagai pemimpin lembaga juga bisa menjadi pelayan dan pengayom bagi bawahannya.

Beberapa teori dan jurnal menyebutkan bahwa servant leadership dan komitmen guru memiliki hubungan yang erat. Beberapa penelitian telah membuktikan bahwa peran servant leadership adalah sebagai faktor pendorong dalam menentukan komitmen guru. Penelitian Palta (2018), yang meneliti 149 guru menemukan bahwa komitmen guru dan servant leadership terkait satu sama lain dan memiliki hubungan yang positif. Demikian juga dengan penelitian Mazarei et al. (2013) yang meneliti 205 guru sebagai subjek dimana hasil penelitiannya menemukan bahwa servant leadership memiliki hubungan yang signifikan terhadap komitmen guru. Kemudian Ambali et al. (2011) juga menemukan bahwa servant leadership berpengaruh signifikan terhadap komitmen organisasi.

Selain servant leadership, karakteristik individu juga merupakan salah satu variabel yang menarik untuk diselidiki dalam kaitannya dengan komitmen guru. Karakteristik individu setiap orang berbeda-beda pada setiap individu menciptakan kontribusi yang berbeda juga pada organisasi. Karakteristik individu mendorong seseorang untuk melakukan suatu aktifitas dan perilaku untuk memuaskan kebutuhannya. Guru dengan karakteristik yang baik akan menjadikan guru tersebut lebih mudah dalam mengemban tugas-tugasnya, sehingga komitmen yang dihasilkan menjadi optimal dan sangat baik pengaruhnya bagi organisasi. Begitu juga sebaliknya, guru dengan karakteristik yang buruk akan menghambat tujuan organisasi. Berdasarkan hal itulah organisasi memiliki kriteria tertentu mengenai pegawai yang akan di angkat dan dipekerjakan sesuai dengan kebutuhan organisasi.

Beberapa penelitian juga membuktikan bahwa karakteristik individu berpengaruh terhadap komitmen pegawai diantaranya Bartholomew et al. (2016) mengungkapkan bahwa ada hubungan positif dan signifikansi antara karakteristik personal dan komitmen pegawai. Kemudian Saputra (2014), yang melakukan penelitian di Aditya Beach Resort Lovina Singaraja dimana hasil penelitiannya menyebutkan karakteristik individu berpengaruh terhadap komitmen organisasi di Aditya Beach Resort Lovina Singaraja.

Selanjutnya pendekatan lain dalam hubungannya dengan komitmen guru adalah motivasi kerja. Menurut Mc. Donald, dalam Sardiman (2008:73) menyatakan bahwa motivasi adalah perubahan energi dalam diri seseorang yang ditandai dengan munculnya "feeling" dan didahului dengan tanggapan terhadap adanya tujuan. Dikatakan bahwa individu yang mempunyai motivasi berprestasi yang tinggi akan bertanggung jawab untuk mencari solusi dari tugas maupun permasalahan, merancang ulang dengan segera tujuantujuan yang sulit dicapai, menerima resiko-resiko, dan mempunyai keinginan yang kuat untuk mendapatkan umpan balik dari kinerjanya (Lawson and Shen, 1998).

Pemberian dorongan berupa motivasi dari atasan kepada bawahan yang dilakukan secara terus menerus akan menciptakan hubungan yang baik antara atasan dengan bawahan. Guru yang diberikan dorongan akan merasa diperhatikan, dihargai, dan merasa dilibatkan dalam kegiatan organisasi, kemudian akan tumbuh komitmen terhadap 
organisasi. Olurotimi et al. (2019) melakukan penelitian terhadap 155 guru hasil penelitiannya menunjukan motivasi kerja berpengaruh signifikan terhadap komitmen guru.

Kemudian Siburian et al. (2017) melakukan penelitian terhadap 164 guru menemukan bahwa motivasi kerja berpengaruh positif signifikan terhadap komitmen guru. Terakhir Malela dan Gathumbi (2016) melakukan penelitian tentang motivasi kerja terhadap komitmen kerja pada 25 orang kepala sekolah dan 169 guru dimana hasil penelitiannya menunjukan terdapat pengaruh positif dan signifikan antara motivasi kerja dan komitmen kerja.

Selanjutnya terdapat satu faktor lagi yang menarik dalam kaitannya dengan komitmen guru yaitu kepuasan kerja guru. Kepuasan kerja memperoleh perhatian yang cukup tinggi oleh berbagai kalangan karena berbagai alasan yang terbukti berpengaruh terhadap efektivitas organisasi. Hasibuan (2013:202) menyebutkan "Kepuasan kerja adalah sikap emosional yang menyenangkan dan mencintai pekerjannya". Kepuasan dalam pekerjaan adalah kepuasan kerja yang dirasakan dalam pekerjaan dengan memperoleh hasil kerja, penempatan, peralatan, perlakuan dan suasana iklim kerja yang baik. Sementara kepuasan diluar pekerjaan adalah kepuasan kerja karyawan yang dirasakan diluar pekerjaan dengan besarnya balas jasa yang akan diterima dari hasil kerjanya, agar dia dapat membeli kebutuhan-kebutuhannya.

Kepuasan kerja merupakan salah satu faktor terpenting dalam komitmen seorang guru dikarnakan seorang guru sebagian besar waktunya dihabiskan di sekolah untuk mengajar. Penyebab guru merasa kurang puas dalam bekerja adalah dikarnakan mereka kurang menerima feedback, jarang menerima pujian dari atasan, kemampuan yang tidak tersalurkan, iklim kerja yang tidak mendukung, sedikit kesempatan untuk berkembang dan kebosanan. Guru yang dipenuhi perasaan dan aspirasinya akan memiliki kesetiaan yang tulus dan dapat berdampak baik pada tujuan organisasi. Disinilah pentingnya kepuasan kerja seseorang sehingga organisasi dituntut untuk mempertahankan exsistensinya. Kepuasan kerja yang tinggi akan berdampak pada komitmen guru pada organisasi. Banyak penelitian yang mencoba untuk membuktikannya seperti penelitian Aref \& Aref (2011) melakukan penelitan terhadap 150 guru dan menemukan bahwa ada korelasi yang relatif kuat antara kepuasan kerja dan komitmen guru.

Menurutnya tingkat kepuasan kerja yang lebih tinggi akan mengarah kepada tingkat komitmen organisasi yang lebih tinggi. Sejalan dengan penelitian diatas Ali \& Bashir (2018) dimana subyek dalam penelitiannya adalah 150 orang guru menemukan bahwa kepuasan kerja dan komitmen guru berpengaruh positif signifikan. Kemudian Malik et al. (2010) meneliti 331 guru dan menemukan bahwa kepuasan kerja memiliki pengaruh positif yang signifikan terhadap komitmen guru.

Berdasarkan latar belakang dan identifikasi masalah yang ada, maka permasalahannya dapat dirumuskan sebagai berikut.

1. Apakah terdapat determinasi yang signifikan servant leadership terhadap komitmen guru di SMAN 1 Gianyar?

2. Apakah terdapat determinasi yang signifikan karakteristik individu terhadap komitmen guru SMAN 1 Gianyar?

3. Apakah terdapat determinasi yang signifikan motivasi kerja terhadap komitmen guru di SMAN 1 Gianyar?

4. Apakah terdapat determinasi yang signifikan kepuasaan kerja terhadap komitmen guru di SMAN 1 Gianyar?

5. Apakah terdapat determinasi yang signifikan secara bersama-sama servant leadership, karakteristik individu, motivasi kerja, dan kepuasan kerja terhadap komitmen guru di SMAN 1

\section{METODE}

Metode penelitian; analisis deskriptif, pendekatan kuantitatif, teknik analisis dengan korelasi product moment, determinasi dan regresi dengan menggunakan software SPSS 25.0 for windows dengan pendekatan penelitian ex-post facto dengan sampel yaitu 
sebanyak 66 orang yaitu guru-guru SMAN 1 Gianyar. Alat pengumpul data berupa kuesioner, analisis data dengan teknik regresi sederhana regresi ganda, dan korelasi parsial

\section{HASIL DAN PEMBAHASAN}

Hasil penelitian yang dimaksudkan adalah menyangkut servant leadership, karakteristik individu, motivasi kerja, dan kepuasan kerja terhadap komitmen guru di SMAN 1 Gianyar.

Tabel 4.1

Rangkuman Statistik Deskriptif Variabel Servant Leadership, Karakteristik Individu, Motivasi Kerja, dan Kepuasan Kerja Terhadap Komitmen Guru.

\begin{tabular}{|c|c|c|c|c|c|}
\hline Statistik Variabel & $\mathrm{X} 1$ & $\mathrm{X} 2$ & X3 & $X 4$ & $Y$ \\
\hline $\begin{array}{l}\text { Rerata } \\
\text { (Mean) }\end{array}$ & $0.515^{13}$ & $0.485^{11}$ & $\begin{array}{r}98 \\
.727^{98}\end{array}$ & $\begin{array}{l}{ }^{10} \\
2.515\end{array}$ & $9.030^{10}$ \\
\hline Median & $1.000^{13}$ & $9.000^{10}$ & $.000^{99}$ & $2.000^{10}$ & $8.000^{10}$ \\
\hline Modus & $4.000^{12}$ & $9.000^{10}$ & $0.000^{10}$ & $.000^{98}$ & $4.000^{11}$ \\
\hline $\begin{array}{l}\text { Std.Devi } \\
\text { asi }\end{array}$ & $.438^{10}$ & $218^{7}$ & $580^{3 .}$ & $794^{7 .}$ & $881^{6 .}$ \\
\hline Varians & $8.961{ }^{10}$ & $.100^{52}$ & $.817^{12}$ & $.746^{60}$ & $.353^{47}$ \\
\hline Range & $.000^{51}$ & $.000^{26}$ & $.000^{14}$ & $.000^{38}$ & $.000^{27}$ \\
\hline $\begin{array}{r}\text { Skor } \\
\text { Maksimum }\end{array}$ & 5.000 & $5.00^{12}$ & 5.000 & $9.000^{11}$ & $5.000^{12}$ \\
\hline $\begin{array}{c}\text { Skor } \\
\text { Minimum }\end{array}$ & $4.000^{10}$ & $.000^{99}$ & $.000^{91}$ & $.000^{81}$ & $.000^{98}$ \\
\hline Jumlah & $\begin{array}{c}86 \\
14.000\end{array}$ & 92.000 & $\begin{array}{c}65 \\
16.000\end{array}$ & $\begin{array}{r}67 \\
66.000\end{array}$ & $\begin{array}{r}71 \\
96.000\end{array}$ \\
\hline
\end{tabular}

Tabel 4.2

Ringkasan Hasil Analisis Data Hubungan antar Variabel

\begin{tabular}{|c|c|c|c|c|}
\hline & $\begin{array}{l}\text { Persamaan } \\
\text { Garis Regresi }\end{array}$ & $\begin{array}{c}\text { Ko } \\
\text { efisien } \\
\text { Korelasi }\end{array}$ & $\begin{array}{r}\text { Det } \\
\text { erminasi } \\
(\%)\end{array}$ & $\begin{array}{r}\text { Sumba } \\
\text { ngan Efektif } \\
(\mathrm{SE})(\%)\end{array}$ \\
\hline $\mathrm{X}_{1}$ dengan $\mathrm{Y}$ & $\begin{array}{l}\dot{Y}=63.938+ \\
0,345 X_{1}\end{array}$ & $24^{0,5}$ & $50^{27}$ & 7,64 \\
\hline $\mathrm{X}_{2}$ dengan $\mathrm{Y}$ & $\begin{array}{l}\dot{Y}=40,777+ \\
0,618 X_{2}\end{array}$ & $48^{0,6}$ & $00^{42}$ & 15,16 \\
\hline $\mathrm{X}_{3}$ dengan $\mathrm{Y}$ & $\begin{array}{l}\dot{Y}=8,590+ \\
1,017 X_{3}\end{array}$ & $29^{0,5}$ & $00^{28,}$ & 6,47 \\
\hline $\mathrm{X}_{4}$ dengan $\mathrm{Y}$ & $\begin{array}{l}\hat{Y}=45,967+ \\
0,615 X_{4}\end{array}$ & $97^{0,6}$ & $50^{48,}$ & 28,50 \\
\hline $\begin{array}{r}\mathrm{X}_{1}, \mathrm{X}_{2}, \mathrm{X}_{3}, \mathrm{X}_{4} \\
\text { dengan } \mathrm{Y}\end{array}$ & $\begin{array}{c}\hat{Y}=11,635+ \\
0,096 X_{1}+0,223 \\
X_{2}+0,235 X_{3}+0,361 \\
X_{4}\end{array}$ & $60^{0,7}$ & $80^{57}$ & - \\
\hline Keterangan & $\begin{array}{c}\text { Signifikan } \\
\text { dan Linier }\end{array}$ & $\begin{array}{l}\text { Sig } \\
\text { nifikan }\end{array}$ & - & - \\
\hline
\end{tabular}




\section{SIMPULAN DAN SARAN}

Berdasarkan hasil temuan tersebut dapat disimpulkan bahwa terdapat determinasi yang signifikan antara servant leadership, karakteristik individu, motivasi kerja dan kepuasan kerja terhadap komitmen guru di SMAN 1 Gianyar secara terpisah maupun simultan. Dengan demikian ketiga faktor tersebut dapat dijadikan prediktor tingkat kecenderungan komitmen guru di SMAN 1 Gianyar.

Berdasarkan temuan tersebut, dapat disarankan beberpa hal sebagai berikut.

1. Kepala sekolah yang memiliki kepemimpinan pelayan (Servant Leadership) berada pada kategori sangat baik oleh karena itu sebagai kepala sekolah untuk tetap menerapkan dan meningkatkan kepemimpinan pelayan yang dimilki agar apa yang menjadi tujuan sekolah bisa terwujud.

2. Kepala sekolah agar selalu memberikan motivasi kepada guru untuk meningkatkan potensi yang dimiliki dan tetap antusias dalam bekerja sehingga dapat mewujukan tujuan yang ingin dicapai sekolah dengan memilki karakteristik individu yang mendukung suatu kegiatan dengan begitu menghasilkan rasa kepuasan dalam bekerja sehingga dapat meningkatkan komitmen guru.

Kepada peneliti lain disarankan agar penelitian ini nantinya dapat digunakan untuk referensi bagi penelitian selanjutnya, karena secara empirik ditemukan bahwa variabel servant leadership, karakteristik individu, motivasi kerja dan kepuasan kerja berdeterminasi secara signifikan terhadap komitmen guru di SMAN 1 Gianyar. Dimana keempat variabel tersebut sudah sepenuhnya berdetermiinasi dengan komitmen guru, maka dari itu perlu diadakan penelitian lebih lanjut tentang berbagai faktor yang diduga berdeterminasi terhadap komitmen guru dengan melibatkan variabel-variabel lain dan dapat dimanfaatkan sebagai pijakan untuk melakukan perbaikan-perbaikan guna meningkatkan komitmen guru

\section{DAFTAR RUJUKAN}

Agung, A.A.G. 2017. Metodologi Penelitian Kuantitatif. Singaraja: Universitas Pendidikan Ganesha.

Agung, Ngurah.2015."Pengaruh Karakteristik Individu Terhadap Komitmen Organisasi Karyawan Aditya Beachresort Lovina Singaraja Tahun 2014". Voume 5, Nomor 1 (hal 104-108).

Ali M., H., Bashir I., 2018. The effect of job satisfaction on teacher's organizationalcommitment, with special reference to private sector universities of Punjab, Pakistan. International Journal of Scientific and Research Publications, Volume 8, Issue 3, March 2018 ISSN 2250-3153

Ambali A., R., Suleiman G., E., Bakar A., N., Hashim R., Tariq Z., 2011. Servant Leadership's Values and Staff's Commitment: Policy Implementation Focus. American Journal of Scientific Research ISSN 1450-223X Issue 13 (2011), pp.18-40 Euro Journals Publishing, Inc. 2011.

A.M., Sardiman. 2008. Interaksi dan Motivasi Belajar Mengajar. Jakarta: Raja Grafindo Persada.

Aref K., Aref A., 2011. The Relationship between Job Satisfaction and Organizational Commitment amongst School Teachers in Shiraz, Iran. Journal of American Science, $2011 ; 7(12)$.

Bartholomew E.,C., Awa H., O., Ukoha O., 2016. Personality Characteristics And Employee Affective Commitment: Nigeria Experience. International Journal of Business and Management Review Vol.4, No.6, pp.69-92, August 2016. Published by European Centre for Research Training and Development UK. 
Colquitt, J.A., Lepine, J.A., \& Wesson, M.J. 2009. Organizational behavior: Improving Performance and Commitment in the Workplace. McGrawHill.

Greenleaf, R.K. (1970). The Servant as Leader. The Robert K Greenleaf Center. Indianapolis.

Hasibuan, Malayu. 2013. MSDM. Jakarta : Bumi Aksara.

Hutama, Firmananda 2016. "Pengaruh Kepuasan Kerja Terhadap Komitmen Organisasi Dan Kinerja Karyawan (Studi Pada Karyawan Tetap PG Kebon Agung Malang)". Jurnal Administrasi Bisnis, Volume 38,Nomor 2 (Hal 84-87).

Lawson R.,.B., Shen Z., 1998. Organizational Psychology: Foundation and Applications. New York: Oxford University Press.

Malela P., K., Gathumbi M., A., 2016. Influence of Inspirational Motivation on Teachers' Job Commitment in Public Primary Schools in Matinyani Sub County, Kitui County, Kenya. International Journal of Humanities and Social Science Invention Volume 5 Issue 10 October. 2016 PP.33-40. ISSN (Online): 2319 - 7722.

Malik, M. E., Nawab, S., Naeem, B., \& Danish, R. Q. 2010. Job satisfaction and Organizational Commitment of University Teachers in Public Sector of Pakistan. International Journal of Business and Management, 5(6), 17-26.

Olurotimi O., J., Asad K., W., Abdulrauf A., 2019. Motivational Factors and Teachers Commitment in Public Secondary Schools in Mbale Municipality. Journal of Education and Practice ISSN 2222-288X (Online) Vol.6, No.15, 2015.

Palta A., 2018. Examination of Teacher's Perceptions about Servant Leadership and Organizational Commitment. International Education Studies; Vol. 12, No. 4; 2019 ISSN 1913-9020 E-ISSN 1913-9039 Published by Canadian Center of Science and Education.

Saputra G., A., N., 2014. Pengaruh Karakteristik Individu Terhadap Komitmen Organisasi Pada Karyawan Aditya Beach Resort Lovina, Singaraja. Vol 5, No 1 2015. Jurnal Jurusan Pendidikan Ekonomi.

Siburian, T. A, Sari, R. F., Wau, Y. (2017). The Effect Of Work Discipline, Job Satisfaction And Work Motivation Towards Teacher Organizational Commitment In Smp Negeri Of Medan Kota District, IOSR Journal of Research \& Method in Education (IOSR-JRME) eISSN: 2320-7388,p-ISSN: 2320-737X Volume 7, Issue 5 Ver. I - PP 45-54. 